\title{
Effects of alfa-hydroxy-isocaproic acid on body composition, DOMS and performance in athletes
}

\author{
Antti A Mero ${ }^{1 *}$, Tuomo Ojala ${ }^{1}$, Juha J Hulmi ${ }^{1}$, Risto Puurtinen ${ }^{1}$, Tuomo AM Karila ${ }^{2,3}$, Timo Seppälä ${ }^{4}$
}

\begin{abstract}
Background: Alfa-Hydroxy-isocaproic acid (HICA) is an end product of leucine metabolism in human tissues such as muscle and connective tissue. According to the clinical and experimental studies, HICA can be considered as an anti-catabolic substance. The present study investigated the effects of HICA supplementation on body composition, delayed onset of muscle soreness (DOMS) and physical performance of athletes during a training period.

Methods: Fifteen healthy male soccer players (age 22.1+/-3.9 yr) volunteered for the 4-week double-blind study during an intensive training period. The subjects in the group HICA $(n=8)$ received $583 \mathrm{mg}$ of sodium salt of HICA (corresponding $500 \mathrm{mg}$ of HICA) mixed with liquid three times a day for 4 weeks, and those in the group PLACEBO $(n=7)$ received $650 \mathrm{mg}$ of maltodextrin mixed with liquid three times a day for the same period. According to a weekly training schedule, they practiced soccer 3 - 4 times a week, had strength training 1 - 2 times a week, and had one soccer game during the study. The subjects were required to keep diaries on training, nutrition, and symptoms of DOMS. Body composition was evaluated with a dual-energy X-ray absorptiometry (DXA) before and after the 4-week period. Muscle strength and running velocity were measured with field tests.

Results: As compared to placebo, the HICA supplementation increased significantly body weight $(p<0.005)$ and whole lean body mass $(p<0.05)$ while fat mass remained constant. The lean body mass of lower extremities increased by $400 \mathrm{~g}$ in HICA but decreased by $150 \mathrm{~g}$ in PLACEBO during the study. This difference between the groups was significant $(p<0.01)$. The HICA supplementation decreased the whole body DOMS symptoms in the $4^{\text {th }}$ week of the treatment $(p<0.05)$ when compared to placebo. Muscle strength and running velocity did not differ between the groups.
\end{abstract}

Conclusion: Already a 4-week HICA supplementation of $1.5 \mathrm{~g}$ a day leads to small increases in muscle mass during an intensive training period in soccer athletes.

\section{Background}

DL- $\alpha$-hydroxy-isocaproic acid (HICA), also known as leucic acid or DL-2-hydroxy-4-methylvaleric acid, is an end product of leucine metabolism in human tissues such as muscle and connective tissue [1,2]. Some foodstuffs produced by fermentation, e.g. certain cheeses, wines and soy sauce contain HICA [3-7]. According to the clinical and experimental studies HICA can be considered as an anti-catabolic substance [8-15]. There is an evidence of a direct in vitro inhibitory effect of HICA on various matrix metalloproteinase enzymes, which are responsible for degradation of various connective and protein tissues [14]. The delayed onset of muscle

\footnotetext{
*Correspondence: antti.mero@sport.jyu.fi
'Department of Biology of Physical Activity, University of Jyväskylä, Jyväskylä,

*Correspondence: antti.mero@sport.jyu.fi
'Department of Biology of Physical Activity, University of Jyväskylä, Jyväskylä, Finland
}

(c) 2010 Mero et al; licensee BioMed Central Ltd. This is an Open Access article distributed under the terms of the Creative Commons Attribution License (http://creativecommons.org/licenses/by/2.0), which permits unrestricted use, distribution, and reproduction in any medium, provided the original work is properly cited. fort and pain during active contractions that occurs in a delayed fashion after strenuous exercise. Subjects with DOMS have painful, tender, and swollen muscles with reduced range of motion of adjacent joints especially after unaccustomed exercise $[16,17]$. In addition to muscle tenderness with palpation, prolonged strength loss and a reduced range of motion are observed. These symptoms develop 24 to 48 hours after exercise, and they disappear within 5 to 7 days $[16,17]$. The pathophysiology of DOMS remains still undetermined, but it has been reported that after strenuous exercise muscle cell damage and inflammatory cells are observed in damaged muscle [16,17].

Although leucine has a unique role as a promoter of protein synthesis [18], maybe especially the metabolites 
of leucine decrease breakdown of proteins, particularly muscle proteins [11]. The roles and mechanisms of actions of leucine and its metabolites are not clear and even confusing. For instance, $\alpha$-ketoisocaproate (KIC), derived from leucine by transamination, is anti-catabolic and reduces muscle protein degradation when given as intravenous infusion [11]. On the other hand, it is a potent inhibitor of branched-chain $\alpha$-keto acid dehydrogenase kinase and may lead to increased catabolism of branched chain amino acids (BCAAs) [19]. $\beta$-Hydroxy $\beta$-methylbutyric acid (HMB) or $\beta$-hydroxy $\beta$-methylbutyrate is another metabolite of leucine and plays also a role in protein synthesis and breakdown [20]. Recently [21], it was observed that 14 of HMB and KIC supplementation reduced signs and symptoms of exerciseinduced muscle damage in non-resistance trained males following a single bout of resistance exercise emphasizing eccentric contractions.

There are separate mechanisms to control protein synthesis and proteolysis [22]. Tischler et al [11] suggested that the first step in controlling muscle proteolysis by leucine is the oxidation of leucine, catalyzed by aminotransferase enzyme. The end product of the reaction is keto leucine ( $\alpha$-ketoisocaproate, KIC) but, in certain situations, it can be HICA as well. It is suggested that the aminotransferase enzyme is responsible to oxidize leucine both to its keto (KIC) and to its hydroxyl form (HICA) and both reactions are reversible [23]. The reaction between keto and hydroxyl leucine is an equilibrium reaction with oxidoreduction equilibrium constant (thermodynamic constant) $\mathrm{Keq}=3.1 \pm 0.2 \times 10$ $12 \mathrm{~mol} / \mathrm{l}$ and the reaction half time is $230 \mathrm{~min}$ towards oxygenation in human. Keto acid is irreversibly oxidized by mitochondrial ketoacid dehydrogenaze [24]. Irreversible degradation of keto acids is higher in liver than that in muscle [24]. The branched-chain $\alpha$-keto acid dehydrogenase complex is the most important regulatory enzyme in the catabolism of leucine [25]. The skeletal muscle is considered to be the initial site of BCAA catabolism because of its high activity of BCAA aminotransferase [2].

In our open pilot study with wrestlers [15; unpublished] we assessed the effects of HICA on body composition and exercise induced DOMS. National top wrestlers $(\mathrm{n}=7,79.7 \pm 4.5 \mathrm{~kg}, 26 \pm 6$ yrs $)$ took $0.496 \mathrm{~g}$ of HICA three times per day after intensive training sessions for 42 days. They had at least 10 training sessions a week, each lasting from 1.5 to 2.5 hours. Since the subjects were competitive athletes they had records on their weights for years during their competition careers. During six weeks before the HICA period there were no essential changes in their weights. At least for the 6week period before and during the 42-day trial daily diets and the number, intensity, and duration of daily training sessions of wrestlers were kept constant. According to DXA measurements the mean body weight gain during the treatment period was $0.84 \pm 1.0 \mathrm{~kg}$ ( \pm $\mathrm{SD})$. Bone mass was not changed but total lean soft tissue mass was increased statically significantly. The most important finding of the pilot study was, however, that subjects when using HICA did not suffer from DOMS symptoms at all or they suffered markedly less than before the treatment with HICA. No changes in blood pressure, heart rate or laboratory blood values were associated with the use of HICA suggesting that its use is safe.

Consequently, the aim of this study was to investigate the effects of HICA supplementation on body composition, DOMS symptoms and physical performance during a controlled one month training period in soccer players. Our hypothesis was that HICA would increase total lean soft tissue mass, would decrease DOMS symptoms and would improve physical performance during training.

\section{Methods \\ Subjects}

The subjects were fifteen healthy male soccer players (age $22.1 \pm 3.9 \mathrm{yr}$ ) in the local club. They signed a written consent which was approved by the local University Ethics Committee.

\section{Study design}

This study was a double-blind, randomized, placebo controlled experiment. At the beginning of study the subjects were randomized to two groups: group HICA; $\mathrm{n}=8$, age $22.8 \pm 6.4 \mathrm{yr}$, height $178.9 \pm 6.8 \mathrm{~cm}$, body fat $14.1 \pm 3.9 \%$ and group PLACEBO; $\mathrm{n}=7$; age $21.3 \pm 2.3$ yr, height $178.4 \pm 5.1 \mathrm{~cm}$, body fat $12.5 \pm 3.0 \%$; mean \pm SD. There were no differences in baseline parameters between the groups. The loading period with HICA or PLACEBO lasted four weeks and the similar tests were performed before and after the loading period. The subjects were familiarized with the tests well because similar tests were used in their normal training.

\section{Loading}

The subjects in the HICA group ingested DL- $\alpha$ hydroxy-isocaproic acid (alfaHICA ${ }^{\mathrm{mi}}$ Elmomed Ltd, Helsinki, Finland) and the subjects in the PLACEBO group received maltodextrin (Manninen Nutraceuticals Ltd, Oulu, Finland). Both supplements were powders and three doses each were ingested per day. One HICA dose was $583 \mathrm{mg}$ as sodium salt (corresponding $500 \mathrm{mg}$ of HICA) mixed with juice or water. One PLACEBO dose included $650 \mathrm{mg}$ maltodextrin mixed also with juice or water. Both powders were scaled and packed ready for the subjects in $1.5 \mathrm{ml}$ Eppendorf tubes. The supplements were advised to ingest three times per day in equal time intervals with meals. 


\section{Training}

Training consisted of 5-7 training sessions per week including 3-4 soccer sessions, 1-2 resistance exercise sessions, and one match. Resistance exercise session included both maximal strength and speed-strength exercises. All subjects were advised to keep training diaries on which they marked all training exercises as well as subjective evaluation of training alertness and the morning onset of delayed muscle soreness (DOMS) in lower and upper extremities. In both assessments the scale was from 1 to 5 where 5 is the best training alertness and the strongest soreness in the muscles. It has been shown earlier that a correlation coefficient between repeated measurements of muscle soreness is good $(\mathrm{r}=$ 0.96; [26]). Each subject was individually supervised how to keep training diaries and to report DOMS.

\section{Nutrition}

Before the beginning of the study, each subject was supervised to continue his normal sport nutrition program. On the testing day the subjects were supervised not to use any sport or dietary supplements. They were supervised also to keep food diaries for five days in the 4-week period for what they were provided with specific verbal and written instructions and procedures for reporting detailed dietary intake, including how to record portions by using household measures, exact brand names and preparation techniques. Dietary intake of the subjects was registered for five days including Saturday and Sunday. The food diaries were analyzed using the Micro Nutrica nutrient-analysis software (version 3.11, Social Insurance Institution of Finland).

\section{Data collection and analysis}

Each subject was tested before and after the 4-week (28 days) loading period at the same time of day (Figure 1).

\section{Blood sampling}

In the morning blood samples were taken from an antecubital vein in the sitting position. Two milliliters blood from a vein was taken in K2 EDTA tubes (Terumo Medical Co., Leuven, Belgium) for measurements of hemoglobin and hematocrit concentration with a Sysmex KX 21N Analyzer (Sysmex Co., Kobe, Japan). The intra-assay coefficient of variation $(\mathrm{CV})$ was $1.5 \%$ for hemoglobin and $2.0 \%$ for hematocrit. After the $400 \mathrm{~m}$ running test (immediately, $5 \mathrm{~min}$ and $30 \mathrm{~min}$ ) five milliliters of blood was taken in lithium-heparin tubes (Terumo Medical Co., Leuven, Belgium) for measurement of lactate (Biosen C line, Sport; EKF Magdeburg, Germany) and $\mathrm{pH}$ with a Nova Biomedical STAT Profile PhOX Plus L Analyzer (Nova Biomedical, Waltham, MA, USA). The intra-assay CV was $3.0 \%$ for lactate and $0.1 \%$ for $\mathrm{pH}$.

\section{Body composition}

Total body composition changes were determined using a dual-energy X-ray absorptiometry device (DXA; Lunar Prodigy Densitometer, GE Lunar Corporation, Madison, WI, USA). This method can differentiate total body bone mineral density (BMD), total percentage fat, total body tissue mass, fat mass, lean mass, bone mineral content (BMC), and total bone calcium with CVs of $0.62,1.89,0.63,2.0,1.11,1.10$, and $1.09 \%$, respectively [27]

\section{Jumping ability}

Maximal standing 5-jump was used to measure explosiveness of leg extensor muscles in horizontal direction [28]. Maximal vertical jumping ability was measured using a counter movement jump (CMJ) on a contact mat with a clock [29]. In both indoor tests the best performance of three trials (recovery from 3 to 5 minutes between the trials) was selected for the final analysis.

\section{Running tests}

Both $20 \mathrm{~m}$ and $400 \mathrm{~m}$ run were performed indoors. Acceleration running speed was measured with a standing start over $20 \mathrm{~m}$. The subject was standing $0.7 \mathrm{~m}$ from the first photocell gate and then accelerated maximally over $20 \mathrm{~m}$ to the second photocell gate (accuracy of $0.01 \mathrm{~s}$ in time measurement). The fastest run of three trials (recovery 5 minutes) was selected to the final analysis. The indoor track was $200 \mathrm{~m}$ on which each subject ran alone maximally $400 \mathrm{~m}$. Running times were

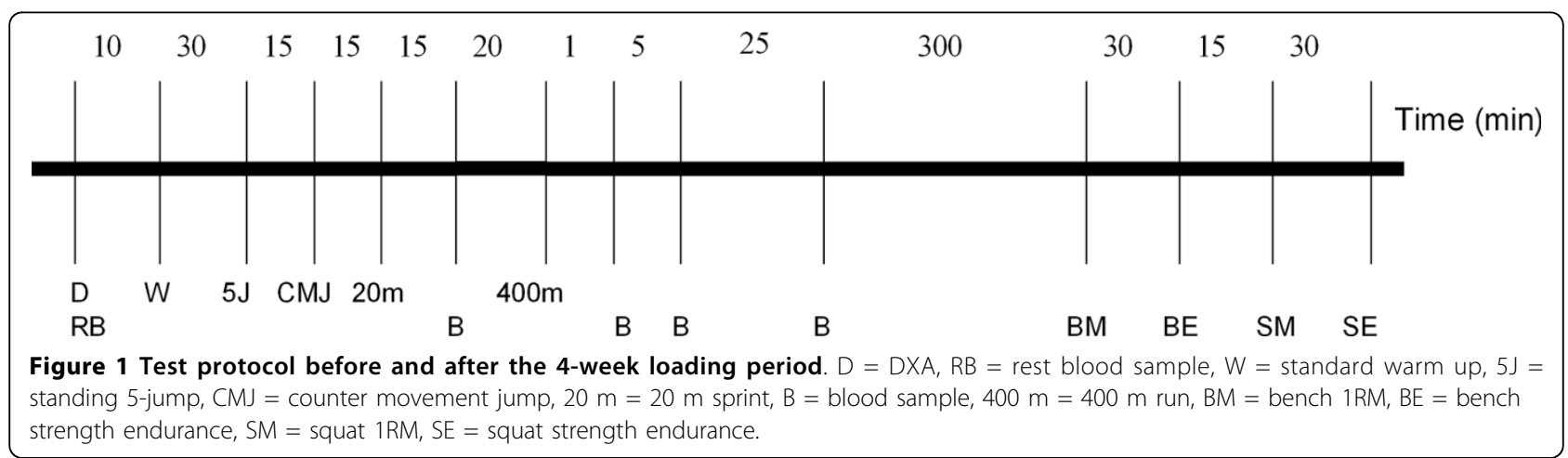


recorded with stopwatches by two experienced investigators, and a mean performance time (accuracy of $0.1 \mathrm{~s}$ ) was calculated for the analysis. Subjects were instructed and verbally encouraged to give a maximal effort for the performance.

\section{Strength tests}

Maximum strength (1RM) was measured in bench press with a free barbell and in full squat using a Smith machine. Strength endurance was measured performing as many repetitions as possible using a $50 \%$ load of $1 \mathrm{RM}$ in both bench press and in full squat. The test order was as follows: bench press $1 \mathrm{RM}$, bench press strength endurance, full squat $1 \mathrm{RM}$, and full squat strength endurance. Recoveries between trials were from three to five minutes in each test and at least five minutes between different tests. Continuous verbal encouragement was given during all the test performances.

\section{Statistical Analyses}

The Analysis of Variance (A Group-by-Time Factorial ANOVA) was used to assess statistical differences between the treatment groups. Data were handled as changes between the measurements before and after the treatments. Further, bonferroni corrected paired t-test was used to compare values before and after treatments. $\mathrm{P} \leq 0.05$ was regarded as statistically significant. Statistical analyses were carried out using the software program Systat for Windows (Statistics, Version 9, Evanston, IL, USA, 1992). The results are presented as means \pm SD.

\section{Results}

\section{Training and Nutrition}

There were no differences in training between the groups of HICA and PLACEBO during the 4-week study period. The training amount across the study period consisted of $13 \pm 3$ soccer sessions, $4 \pm 1$ strength training sessions and $3 \pm 1$ matches.

The subjects ate similarly in both groups and the average daily macronutrient intake during five days across the 4-week study period was as follows: energy $11183 \pm$ $2361 \mathrm{~kJ}$, protein $119 \pm 37 \mathrm{~g}$, carbohydrate $341 \pm 87 \mathrm{~g}$, and fat $82 \pm 23 \mathrm{~g}$.

\section{Hemoglobin and hematocrit}

There were no differences in hemoglobin or hematocrit between the groups of HICA and PLACEBO or between before and after measurements in each group. The average value for the total subject group was $150 \pm 6.4 \mathrm{~g} / \mathrm{l}$ in hemoglobin and $44 \pm 0.03$ in hematocrit.

\section{Body composition}

Body weight was in the HICA group before and after the 4-week study period $72.6 \pm 9.1 \mathrm{~kg}$ and $72.9 \pm 8.6 \mathrm{~kg}$ and in the PLACEBO group $70.0 \pm 5.2 \mathrm{~kg}$ and $70.1 \pm 5.1 \mathrm{~kg}$, respectively. The difference between the treatments was significant in body weight ( $\mathrm{p}<0.005)$, in whole lean body mass (LBM: before $62.2 \pm 6.7$ and after $62.5 \pm 6.5$ for HICA and before $62.2 \pm 4.9$ and after $62.2 \pm 4.6$ for PLACEBO; $\mathrm{p}<0.05$; Figure 2A) while fat mass remained constant. Also bone mass $(3.6 \pm 0.1 \mathrm{~kg})$ remained constant in both groups. The absolute changes were significant in weight $(\mathrm{p}<0.005)$ and in LBM $(\mathrm{p}<0.05)$ (Figure $2 B)$. The difference between the treatments was significant also in lean body mass of lower extremities $(\mathrm{p}<0.05)$ (Figure 3A). The lean body mass of lower extremities increased by 400 $\mathrm{g}$ in the HICA group but decreased by $150 \mathrm{~g}$ in the PLACEBO group and the changes between the groups differed significantly $(\mathrm{p}<0.01)$ (Figure $3 \mathrm{~B})$. Individual changes in relative LBM of lower extremities are presented in Figure 4. There were no differences between the groups in body composition of upper extremities.

\section{Performance}

The performance variables are presented in Table 1. There were no significant differences between the groups HICA and PLACEBO in any of the variables.

\section{DOMS and training alertness}

The HICA supplementation decreased significantly $(\mathrm{p}<$ 0.05 ) the whole body DOMS symptoms only in the $4^{\text {th }}$
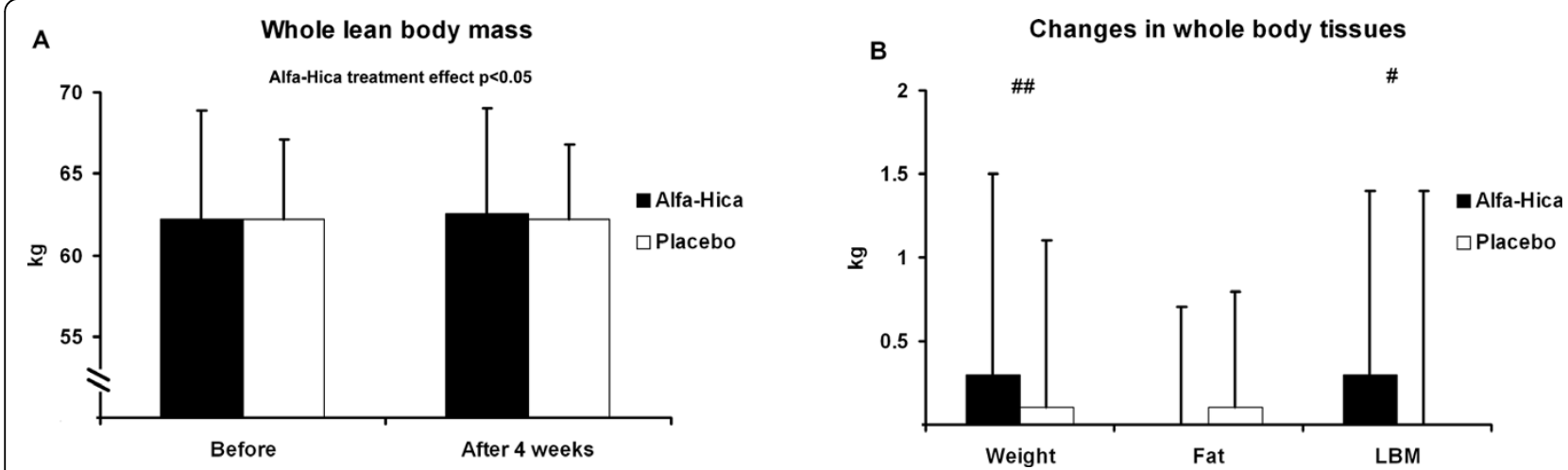

Figure 2 Whole lean body mass (A) and changes in whole body tissues (B). Data are mean \pm SD. \#\# represents $(p<0.005)$ and \# represents $(p<0.05)$ difference in change between before and after measurement between the groups. 


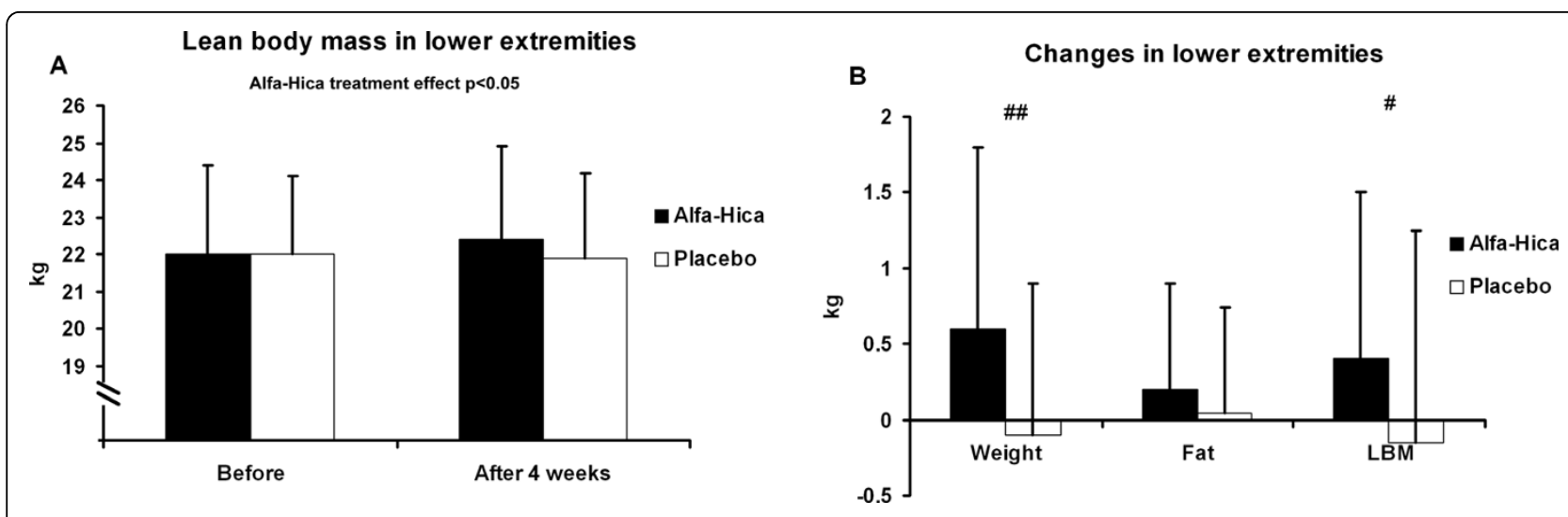

Figure 3 Lean body mass of lower extremities (A) and the changes of its components in lower extremities (B). Data are mean \pm SD. \#\# represents $(p<0.001)$ and \# represents $(p<0.01)$ difference in change between before and after measurement between the groups

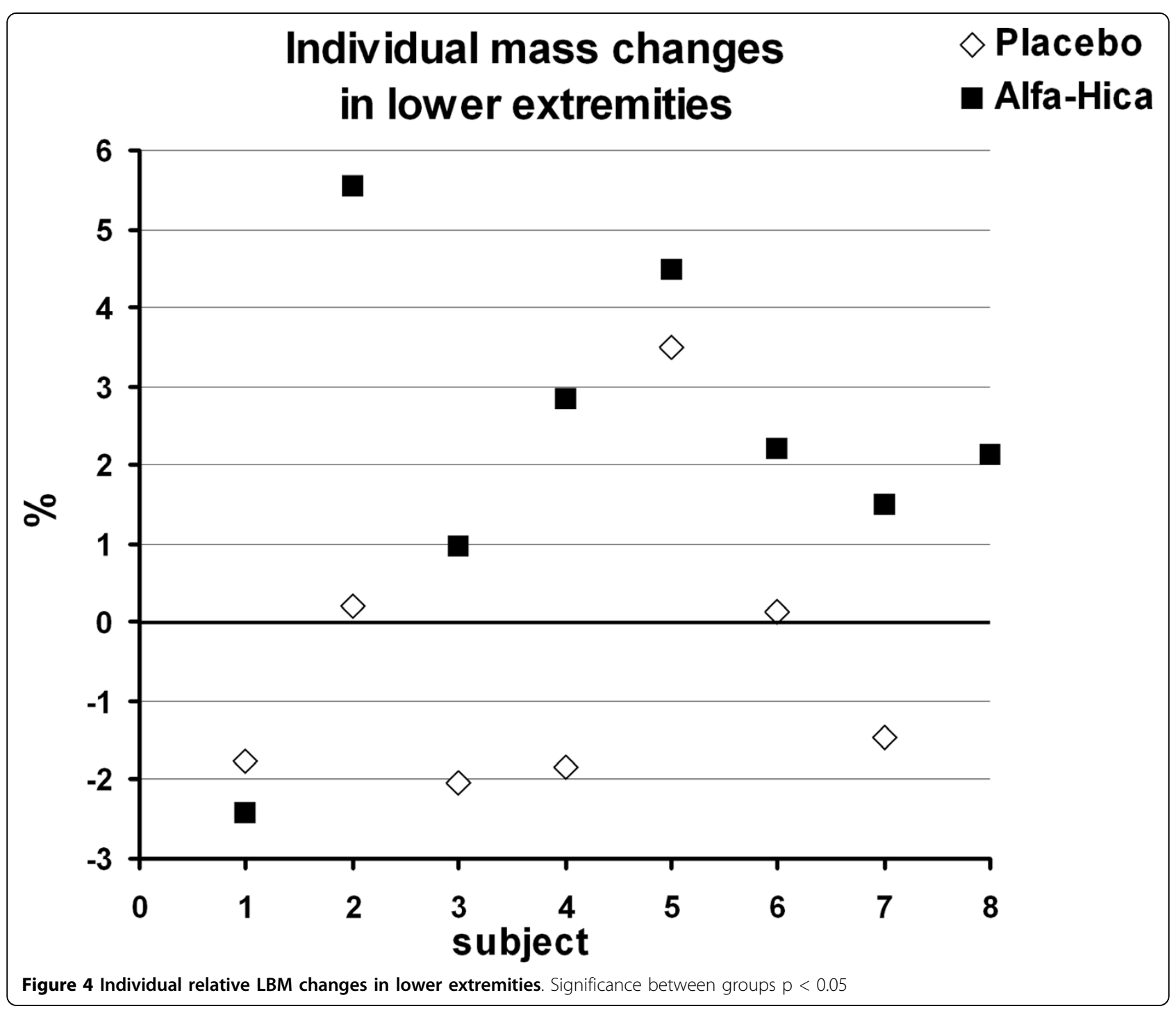


Table 1 Physical performance before and after the 4week period

\begin{tabular}{lcccc}
\hline Variable & \multicolumn{2}{c}{ HICA } & \multicolumn{2}{c}{ PLACEBO } \\
& Before & After & Before & After \\
\hline 5 -jump (m) & $13.44 \pm 0.71$ & $13.80 \pm 0.73$ & $13.22 \pm 0.70$ & $13.63 \pm 0.91$ \\
$\mathrm{CMJ}(\mathrm{m})$ & $43.5 \pm 0.03$ & $42.8 \pm 0.06$ & $42.3 \pm 0.06$ & $44.2 \pm 0.05$ \\
$20 \mathrm{~m} \mathrm{(s)}$ & $3.02 \pm 0.06$ & $3.04 \pm 0.11$ & $2.96 \pm 0.05$ & $2.98 \pm 0.06$ \\
$400 \mathrm{~m} \mathrm{(s)}$ & $61.3 \pm 1.8$ & $61.7 \pm 1.6$ & $60.2 \pm 1.7$ & $59.1 \pm 0.7$ \\
$\mathrm{pH}^{\mathrm{a}}$ & $7.09 \pm 0.11$ & $7.17 \pm 0.12$ & $7.12 \pm 0.12$ & $7.17 \pm 0.12$ \\
lactate (mmol/l) $^{a}$ & $13.6 \pm 1.3$ & $14.5 \pm 2.2$ & $14.4 \pm 2.8$ & $14.2 \pm 2.9$ \\
$\begin{array}{l}\text { Bench press 1RM } \\
\text { (kg) }\end{array}$ & $87.5 \pm 21.0$ & $87.9 \pm 20.9$ & $82.5 \pm 13.5$ & $83.3 \pm 14.6$ \\
$\begin{array}{l}\text { Strength } \\
\text { endurance (reps) }\end{array}$ & $31 \pm 3$ & $32 \pm 4$ & $28 \pm 2$ & $31 \pm 3$ \\
$\begin{array}{l}\text { Full squat 1RM } \\
\text { (kg) }\end{array}$ & $120 \pm 19$ & $130 \pm 24$ & $131 \pm 29$ & $138 \pm 16$ \\
$\begin{array}{l}\text { Strength } \\
\text { endurance (reps) }\end{array}$ & $31 \pm 8$ & $47 \pm 5$ & $36 \pm 10$ & $38 \pm 11$ \\
\hline
\end{tabular}

Data are means $\pm \mathrm{SDs}$. ${ }^{\mathrm{a}} \mathrm{pH}$ is the lowest value and lactate is the highest value after $400 \mathrm{~m}$

week of the treatment $(1.4 \pm 0.3)$ when compared to placebo $(1.8 \pm 0.2)$ (all weeks $1.5 \pm 0.3$ for HICA and $1.7 \pm 0.4$ for PLACEBO; mean $\pm \mathrm{SD}$ ). Training alertness was during every study week slightly better in the HICA group $(3.6 \pm 0.5 ; 4.2 \pm 0.5 ; 4.1 \pm 0.5 ; 4.3 \pm 0.6)$ compared to the PLACEBO group $(3.3 \pm 0.6 ; 3.0 \pm 0.9 ; 3.4$ $\pm 1.1 ; 3.4 \pm 0.8)$ but significantly $(\mathrm{p}<0.05)$ better only in the second week.

\section{Discussion}

Main results

The 4-week supplementation with HICA increased the whole lean body mass of the soccer players. This increase $(400 \mathrm{~g})$ was emphasized in lower extremities. Also the subjects in the HICA group felt milder DOMS compared to the subjects in the PLACEBO group. There were no differences between the groups in any of the performance variables.

\section{Body composition}

The main result of this study was that lean body mass increased with HICA during the 4-week training period. Consequently, it is probable that skeletal muscle mass has increased especially in the lower extremities of the soccer players, because the main training and playing is leg work. The precision of DXA for lean body mass is $1.11 \%$ as we mentioned in the methods. The result in lower extremity change was small - in the HICA group there was a mean increase of $400 \mathrm{~g}(\sim 2 \%)$ and in PLACEBO a decrease of $150 \mathrm{~g}(<1 \%)$. Taking into account this short duration of the experiment period the difference between the groups can be considered rather clear $(550 \mathrm{~g})$. Looking also at the individual mass changes we can see a clear difference between the groups. Only one subject from each group is within another group. Human skeletal muscle protein metabolism has received significant attention over the past few decades because of its relevance to sport, physical inactivity, aging, and disease processes [30]. The importance of skeletal muscle is obvious since it comprises about $40 \%$ of body weight, constitutes between 50 and $75 \%$ of all proteins [31], and is important for locomotion. However, it is also important as an amino acid reservoir, for energy consumption and for fuels for other tissues (e.g., brain, immune cells). Skeletal muscle proteins have regular turnover such that $1-2 \%$ of proteins are synthesized and broken down daily [32]. The turnover of proteins involves the ongoing processes of protein synthesis and breakdown. A positive net protein balance occurs when proteins accumulate in excess of their removal (e.g., following nutrient ingestion), whereas a negative net protein balance occurs when the breakdown of proteins exceeds that of their synthesis (e.g., fasting). Indeed, protein, essential amino acids (particularly leucine) and resistance exercise but also endurance exercise [33] are powerful stimulators of skeletal muscle protein synthesis in animal and human models [34-37] and eventually skeletal muscle hypertrophy [18].

DL- $\alpha$-hydroxy-isocaproic acid (HICA) is a physiological agent which is normally present in the human body in small amounts. Plasma concentration of HICA in healthy adults is $0.25 \pm 0.02 \mathrm{mmol} / \mathrm{l}$, that of its correspondent keto acid is $21.6 \pm 2.1 \mathrm{mmol} / \mathrm{l}$, and in circulation HICA is not bound to plasma proteins [1]. It can be measured from human plasma, urine and amniotic fluid as well [38-40]. It has been earlier [41] speculated that leucine alone accounts for about $60 \%$ of the total effectiveness of the group of the regulatory amino acids (leucine, tyrosine, glutamine, proline, methione, histidine, and tryptophan) to inhibit the deprivation-induced protein degradation in rat liver. The same effect is achieved with HICA alone whereas keto acid of leucine $(\alpha$-ketoisocaproate) does not produce the same effect at normal concentrations [41]. It seems that in the present study the soccer players could benefit the supplementation of HICA. Their average protein intake was already rather high, $1.6-1.7 \mathrm{~g} / \mathrm{kg} /$ day, and the intake of HICA per day was $1.5 \mathrm{~g}$. It can be concluded that ingestion of this extra "amino acid" HICA, even with sufficient daily protein and thus probably also leucine intake, increases lean muscle mass. Probably this increase comes mainly through minimizing catabolic processes induced by exercise but needs further studies.

It must be noticed that the training period was 4 weeks which is very short time to achieve training effects. The training of the soccer players consisted of resistance training (weights) only four times during 28 days whereas 13 soccer units and three matches were 
included. This means that a lot of endurance (both aerobic and anaerobic) type exercises were included and probably catabolic processes in body were quite strong. For this reason HICA might have been efficient in minimizing those processes. The importance of making room for protein in muscle recovery also from endurance exercise in increasing mixed skeletal muscle fractional synthetic rate and whole body protein balance has been actively discussed recently [42,33].

\section{Physical performance}

There were no changes in physical performance in either group during the 4-week period. This period was the last month before the competitive season and the content of the training was planned quite intensive. Consequently, it was probably too short time period to get strong training responses. Notwithstanding the increase in muscle mass of the lower extremities in HICA, full squat (1RM), 5-jump and strength endurance in squat did not improve significantly in the HICA group compared to the PLACEBO group. The reason for this may be the small number of subjects and, on the other hand, physical performance parameters improved slightly in the PLACEBO group, too.

\section{DOMS}

The DOMS symptoms are particularly associated with the eccentric exercise $[16,17]$. In soccer there are a lot of unaccustomed movements (jumps in various situations) and motions (acceleration runs and braking after sprint etc.) and therefore eccentric muscle functions occur. In the present study the players marked on an average points from 1 to 3 out of 5 showing that they had all consistently some DOMS symptoms. During the last $4^{\text {th }}$ study week the subjects of the HICA group felt milder symptoms compared to the subjects in the PLACEBO group. Delayed presentation of the subjective effect could be explained by enzyme inhibition. We don't presently know the exact mechanism of action, but it can be speculated that decreased DOMS symptoms could be due to HICA's direct inhibitory effect on various metalloproteinase enzymes [14]. Training alertness was also increased with concomitant decrease of DOMS symptoms. That effect was significantly noted after the $2^{\text {nd }}$ week in the HICA group and thereafter it seemed to continue up to the last weeks.

Mixture of BCAAs has recently shown to decrease symptoms of DOMS but the most effective ratio of the three BCAAs is unclear [43]. In our pilot study with wrestlers [15; unpublished] the findings with HICA suggested that it alone is highly effective on DOMS symptoms. According to literature such effect has been described previously with the combination of $\alpha$-keto isocaproic acid and $\beta$-hydroxy- $\beta$-methyl butyrate [21]. The mechanism by which HICA alleviates DOMS symptoms is unclear. Future studies are needed to compare the effects of different leucine metabolites, leucine itself and leucine-rich food in humans.

\section{Conclusion}

HICA supplementation of $1.5 \mathrm{~g}$ a day leads to small increases in muscle mass during a four week intensive training period in soccer athletes.

\section{Acknowledgements}

The authors thank the subjects participating in this study, Saana Saltevo who assisted in data acquisition and Mrs Pirjo Luoma for assistance in DXA measurements and analysis.

\section{Author details}

${ }^{1}$ Department of Biology of Physical Activity, University of Jyväskylä, Jyväskylä, Finland. ${ }^{2}$ Hospital Orton, Helsinki, Finland. ${ }^{3}$ Orthopaedic Department, Gisborne Hospital, New Zealand. ${ }^{4}$ Department of Alcohol, Drugs and Addiction, National Institute for Health and Welfare, Helsinki, Finland.

\section{Authors' contributions}

AAM conceived the study, developed the study design, participated in data acquisition and drafting the manuscript. TO developed the study design, participated in the data acquisition and assisted in drafting the manuscript. $\mathrm{JJH}$ assisted with the design of the study, and the manuscript preparation. RP collected blood samples and analyzed them. TS and TAMK assisted with the design of the study and drafting the manuscript. All authors have read and approved the final manuscript.

\section{Competing interests}

The authors Dr, MD Tuomo Karila and Dr, MD Timo Seppälä are inventors of HICA patent of "Nutrient Supplement and use of the same" and also partners at Oy Elmomed Ltd. The Study was conducted at independent research unit and the leader of the study Dr Mero and the other coauthors have no relationships to any studied substances.

Received: 21 October 2009

Accepted: 5 January 2010 Published: 5 January 2010

\section{References}

1. Hoffer LJ, Taveroff A, Robitaille L, Mamer OA, Reimer ML: Alpha-keto and alpha-hydroxy branched-chain acid interrelationships in normal humans. Journal of Nutrition 1993, 123:1513-1521.

2. Holecek M: Relation between glutamine, branched-chain amino acids, and protein metabolism. Nutrition 2002, 18(2):130-133.

3. Yamamoto A: Flavors of sake. II. Separation and identification of a hydroxyl carboxylic acid. Nippon Nogeikagaku Kaishi 1961, 35:619.

4. Van Wyk CJ, Kepner RE, Webb AD: Some volatile components of vitis vinifera variety white riesling. 2 . Organic acids extracted from wine. Journal of Food Science 1967, 32(6):664-668.

5. Begemann WJ, Harkes PD: Enhancing a fresh cheese flavor in foods. U. Lever Brothers Co. U.S 1974.

6. Begemann WJ, Harkes PD: Process for enhancing a fresh cheese flavor in foods. U.S 1974

7. Smit BA, Engels WJ, Wouters JT, Smit G: Diversity of L-leucine catabolism in various microorganisms involved in dairy fermentations, and identification of the rate-controlling step in the formation of the potent flavor component 3-methylbutanal. Appl Microbiol Biotechnol 2004, 64(3):396-402

8. Walser M: Composition for promotion of protein synthesis and suppression of urea formation in the body utilizing alpha-hydroxy-acid analogs of amoni acids. US Patent 14446211973.

9. Walser M: Therapeutic compositions comprising alpha-hydroxy analogs of essential amino acids and their administration to humans for promotion of protein synthesis and suppression of urea formation. US Patent 4100161 U.S., The Johns Hopkins University, Baltimore, Md 1978.

10. Boebel K, Baker D: Comparative utilization of the alpha-keto and D- and L-alpha-hydroxy analogs of leucine, isoleucine and valine by chicks and rats. Journal of Nutrition 1982, 112(10):1929-1939. 
11. Tischler M, Desautels M, Goldberg A: Does leucine, leucyl-tRNA, or some metabolite of leucine regulate protein synthesis and degradation in skeletal and cardiac muscle?. J Biol Chem 1982, 257(4):1613-1621.

12. Lindgren $\mathrm{S}$, Sandberg $\mathrm{G}$, Enekull U, Werner T: Energy substrate containing hydroxycarboxylic acid and a glycerol ester. Kabivitrum Ab Patent number EP 367734 Al 1990.

13. Lindgren $\mathrm{S}$, Sandberg $\mathrm{G}$, Enekull U, Werner T: Energy substrate containing hydroxycarboxylic acid. Kabivitrum Ab Patent number EP 363337 A1 1990.

14. Westermarck HW, Hietala P, et al: Use of alpha-hydroxy acids in the manufacture of a medicament for the treatment of inflammation. Exracta Oy. Patent Number WO 97/00676 1997.

15. Hietala P, Karila T, Seppälä T, Tähtivuori K: Nutrient supplement and use of the same. Patent Number PCT/F/2005/050365 Oy Extracta Itd 2005.

16. Barlas P, Craig JA, Robinson J, Walsh DM, Baxter GD, Allen JM: Managing delayed-onset muscle soreness: lack of effect of selected oral systemic analgesics. Arch Phys Med Rehabilitation 2000, 81:966-972.

17. Lieber L, Friden J: Morphologic and mechanical basis of delayed-onset muscle soreness. J Am Acad Orthop Surg 2002, 10(1):67-73.

18. Hulmi JJ, Kovanen V, Selänne H, Kraemer WJ, Häkkinen K, Mero AA: Acute and long-term effects of resistance exercise with or without protein ingestion on muscle hypertrophy and gene expression. Amino Acids 2009, 37(2):297-308.

19. Shimomura Y, Murakami T, Nakai N, Nagasaki M, Harris RA: Exercise promotes BCAA catabolism: effects of BCAA supplementation on skeletal muscle during exercise. Journal of Nutrition 2004, 134:1583-1587.

20. Wilson GJ, Wilson JM, Manninen AH: Effects on beta-hydroxy-betamethylbutyrate (HMB) on exercise levels of age, sex and training experience: A review. Nutrition \& Metabolism 2008, 5(1):1, 10.1186/17437075-5-1.

21. Van Someren K, Edwards A, Howatson G: Supplementation with betahydroxy-beta-methylbutyrate (HMB) and alpha-ketoisocaproic acid (KIC) reduces signs and symptoms of exercise-induced muscle damage in man. Int I Sport Nutr and Exerc Metab 2005, 15:413-424.

22. Kadowaki M, Kanazawa T: Amino acids as regulators of proteolysis. Journal of Nutrition 2003, 133:2052-2056.

23. Blanchard M, Green DE, Nocito-Carroll V, Ratner S: I-Hydroxy acid oxidase. J. Biol. Chem 1946, 163:137-144.

24. Suryawan A, Hawes JW, Harris RA, Shimomura Y, Jenkins AE, Hutson SM: A molecular model of human branched-chain amino acid metabolism. Am J Clin Nutr 1998, 68(1):72-81.

25. Kobayashi R, Murakami T, Obayashi M, Nakai N, Jaskiewicz J, Fujiwara $Y$, Shimomura Y, Harris RA: Clofibric acid stimulates branched-chain amino acid catabolism by three mechanisms. Arch BiochemBiophys 2002, 15;407(2):231-240

26. Zainuddin Z, Newton M, Sacco P, Nosaka K: Effects of massage on delayed-onset muscle soreness, swelling and recovery of muscle function. Journal of Athletic Training 2005, 40(3):174-180.

27. Kiebzak GM, Leamy LJ, Pierson LM, Nord RH, Zhang ZY: Measurement precision of body composition variables using the lunar DPX-L densitometer. J Clin Densitom 2000, 3(1):35-41.

28. Mero A, Luhtanen P, Viitasalo JT, Komi PV: Relationships between the maximal running velocity, muscle fiber characteristics, force production and force relaxation of sprinters. Scandinavian Journal of Sports Sciences 1981, 3(1):16-22.

29. Komi PV, Bosco C: Utilization of stored elastic energy in leg extensor muscles by men and women. Med Sci Sports 1978, 10(4):261-265.

30. Drummond MJ, Dreyer HC, Fry CS, Glynn EL, Rasmussen BB: Nutritional and contractile regulation of human skeletal muscle protein synthesis and mTORC1 signaling. J Appl Physiol 2009, 106(4):1374-1384.

31. Matthews DE: Proteins and amino acids. Modern Nutrition and Health and Disease Baltimore, MD: Williams \& WilkinsShils ME, Olson JA, Shike M, Ross AC, 9 1999, 11-48

32. Welle S, Thornton C, Statt M, McHenry B: Postprandial myofibrillar and whole body protein synthesis in young and old human subjects. Am J Physiol 1994, 267(4):599-604.

33. Howarth KR, Moreau NA, Phillips SM, Gibala MJ: Coingestion of protein with carbohydrate during recovery from endurance exercise stimulates skeletal muscle protein synthesis in humans. J Appl Physiol 2009, 106(4):1394-402.

34. Anthony JC, Yoshizawa F, Anthony TG, Vary TC, Jefferson LS, Kimball SR: Leucine stimulates translation initiation in skeletal muscle of postabsorptive rats via a rapamycin-sensitive pathway. JNutr 2000, 130(10):2413-2419.

35. Tipton KD, Wolfe RR: Exercise, protein metabolism, and muscle growth. Int J Sport Nutr Exerc Metab 2001, 11(1):109-132.

36. Dreyer HC, Fujita S, Cadenas JG, Chinkes DL, Volpi E, Rasmussen BB: Resistance exercise increases AMPK activity and reduces $4 \mathrm{E}-\mathrm{BP} 1$ phosphorylation and protein synthesis in human skeletal muscle. $J$ Physiol 2006, 15(576):613-624.

37. Fujita S, Dreyer HC, Drummond MJ, Glynn EL, Cadenas JG, Yoshizawa F, Volpi E, Rasmussen BB: Nutrient signalling in the regulation of human muscle protein synthesis. J Physiol 2007, 15;582(Pt 2):813-823.

38. Lancaster G, Mamer OA, Scriver CR: Branched-chain alpha-keto acids isolated as oxime derivatives: relationship to the corresponding hydroxy acids and amino acids in maple syrup urine disease. Metabolism 1974 23(3):257-265.

39. Jakobs C, Sweetman L, Nyhan WL: Hydroxy acid metabolites of branchedchain amino acids in amniotic fluid. Clin Chim Acta 1984, 140(2):157-166.

40. Mamer OA, Laschic NS, Scriver CR: Stable isotope dilution assay for branched chain alpha-hydroxy-and alpha-ketoacids: serum concentrations for normal children. Biomed Environ Mass Spectrom 1986, 13(10):553-558.

41. Mortimore GE, Pösö AR, Kadowaki M, Wert JJ Jr: Multiphasic control of hepatic protein degradation by regulatory amino acids. General features and hormonal modulation. J Biol Chem 1987, 5;262(34):16322-16327.

42. Rodriguez NR: Making room for protein in approaches to muscle recovery from endurance exercise. J Appl Physiol 2009, 106(4):1036-1037.

43. Shimomura Y, Yamamoto Y, Bajotto G, Sato J, Murakami T, Shimomura N, Kobayashi H, Mawatari K: Nutraceutical effects of branched-chain amino acids on skeletal muscle. J Nutr 2006, 136(2):529-532.

doi:10.1186/1550-2783-7-1

Cite this article as: Mero et al:: Effects of alfa-hydroxy-isocaproic acid on body composition, DOMS and performance in athletes. Journal of the International Society of Sports Nutrition 2010 7:1.

\section{Publish with Biomed Central and every scientist can read your work free of charge}

"BioMed Central will be the most significant development for disseminating the results of biomedical research in our lifetime. "

Sir Paul Nurse, Cancer Research UK

Your research papers will be:

- available free of charge to the entire biomedical community

- peer reviewed and published immediately upon acceptance

- cited in PubMed and archived on PubMed Central

- yours - you keep the copyright
BioMedcentral 